\title{
Enhancing Research Competences in Healthcare Higher Education
}

\author{
Andrew Sirkka ${ }^{1,3}$, Juraj Čáp ${ }^{2,3}$ \\ ${ }^{1}$ Faculty of Health, Satakunta University of Applied Sciences, Pori, Finland \\ ${ }^{2}$ Department of Nursing, Jessenius Faculty of Medicine in Martin, \\ Comenius Univeristy in Bratislava, Slovakia \\ ${ }^{3}$ Centre for Science and Research, Faculty of Health Sciences, Palacký University, Olomouc, Czech Republic
}

\begin{abstract}
Background: In evidence-based education, experts are supposed to possess skills and content knowledge. Scientific skills provide the tools and ways of thinking that enable researches to build the robust conceptual frameworks needed to gain expertise. Science education should not only provide broad content knowledge base but also develop analytical thinking, understanding of scientific research processes, and inspire curiosity of researchers.

Objectives: This paper discusses the key results of subjective evaluation of attained outcomes of a 2,5-year project focused on enhancing research competences in a faculty of health sciences.

Methods: The data was gathered from project members by four consequent semi-structured online questionnaires. Total number of respondents was $78(\mathrm{~N}=78)$ with $75 \%$ response rate. The data was analysed by a summative content analysis combining quantitative and qualitative analyses.

Results: The findings present evident progress in personal achievements, team working, and scientific practice in the faculty. Based on identified needs the concrete measures supported learning and lead to enhancement in the target group's research competences.

Conclusions: Capacity building approach was successful in laying a robust foundation for consistent development in research-based practice both in academic and professional levels. Further research should be conducted on the long-term impacts of the project in the faculty.
\end{abstract}

\section{KEY WORDS}

research competences, capacity building, self-assessment, organisational learning, evidence-based practice

\section{INTRODUCTION}

Huge amount of economic and human resources are spent in research worldwide. Research is increasingly making inroads into all professional practice. Professionals are encouraged or even expected to show evidence of their inputs and outputs which is why various types of data need to be gathered constantly from one's own practice. Today's professional practice is expected to be evidence-based, well documented, transparent and updated by translating and transferring the latest research evidence into daily activities and decision-making $(1,2,3,11$, $17,18)$. In order to meet this requirement, more focus in various educational levels, including professional continuous education, is set on developing scientific and research competences $(4,5,6,8,15$, $17,18,25)$.
The term competence is defined as the quality or state of being functionally adequate, a sufficiency of means for the necessities, the knowledge that enables a person, or the ability to do something well, the quality or state of being competent. Research competence means certain skills, knowledge and attitudes that enable a person to conduct a systematic and critical investigation of phenomena, to identify problems and issues, and ask appropriate research questions in order to increase knowledge and understanding. The adequate level of research skills assist to critically investigate issues, generate and evaluate relevant data, form and test ideas, theories and hypotheses to establish a successful research design $(7,8,9,10,17,18)$.

Scientific or research competences consist of various skills required to question, assess and evaluate critically, to do science, research and instrumenta- 
tion, organisation skills to systematically collect, analyse and interpret data, to design experimental settings, to communicate in terms of scientific writing and oral presentations, and to collaborate with other actors. Scientific competence is also an ability to organise and manage time, apply science to professional life, to teach professionals, to transfer research-based knowledge into interdisciplinary practice. $(8,11,16,17,20$.)

Within healthcare, the concepts of research (RBP) or evidence-based practice - (EBP) have been developed to supply best evidence in conjunction with clinical expertise and patient values to guide health care decisions and practices $(14,17,18)$. Best evidence includes empirical evidence from randomised controlled trials or descriptive and qualitative research findings. The practice should be guided by adequate research evidence in conjunction with clinical expertise and patient values $(7,5,12,11,19)$. Several barriers to implementation of evidence-based practice are repeatedly mentioned in research findings. Lack of time, knowledge and tools, role strains, attitude and respect issues $(18,19)$ experienced by healthcare professionals cause the failure to translate research into practice and policy $(13,18,19)$.

In evidence-based education, experts are supposed to possess both skills and content knowledge $(7,8,17)$. Although content is clearly important, scientific skills provide the tools and ways of thinking that enable researches to build the robust conceptual frameworks needed to gain expertise. Science education should not only provide broad content knowledge base but also develop analytical thinking skills, offer understanding of the scientific research process, inspire curiosity, and be accessible to a diverse range of young researchers. $(2,14,15,21)$.

\section{Capacity building project on scientific competences}

Capacity building projects are seen as an effective way to achieve new competences and generate expected changes in professional communities $(6,11,17,21,25,26)$. The aim of the Project „Support of Human Resources in Science and Research in Non-medical Health Care at the Faculty of Health Sciences at Palacký University Olomouc" (CZ.1.07/ 2.3.00/20.0163) was to create conditions to enhance scientific potential among the academic staff and students in the Faculty of Health Sciences at the target university. The $2 \frac{1}{2} 2$-year project consisted of five (5) key activities (KA):

1) establishing the Centre for Excellence in Science and Research in Non-medical Healthcare at the Faculty of Health Sciences (KA1),

2) increasing science and research competences and skills in Evidence Based Practice in the academic community (KA2),

3) developing implementation of international nursing terminology in the Czech environment (KA3),

4) enhancing scientific application of social and psychological aspects in non-medical health care (KA4),

5) promoting and developing scientific procedures in the research of physical therapy (KA5).

The key activities were designed especially as concrete action steps to make a difference as to the above mentioned evidenced constraints in implementation of research and evidence-based practice in general.

The objectives of the project were to create conditions for enhancement of a team of experts to carry out research and expedite knowledge transfer, to make a difference in the academic culture and atmosphere in regard with evidence-based practice, scientific writing and methodological literacy in the target faculty as well as improve the quality of students' theses with increased level of research competences among students.

The project consisted of activities like organising education, mentoring and workshops for faculty members on evidence-based practice, research methodologies, and scientific writing. The education part contained various courses and seminars run by international and national experts. Numerous hands-on small group sessions and workshops were organised where experts assisted and advised in assignments. The project also supported participation in special courses or scientific conferences abroad. In numerous workshops over the project period, the academic staff worked on the ways to integrate research and evidence based practice into teaching, how to intensify supervision processes of student dissertations as well as got practical assistance and support in how to write, publish and present scientific articles and other presentations.

\section{OBJECTIVES}

This paper describes the progress of subjective self-assessment and describes the main results regarding the project members' personal and team achievements in regard with scientific competences over the 2,5-year period of the Project "Support of Human Resources in Science and Research in Non-medical Health Care at the Faculty of Health Sciences at Palacký University Olomouc" (CZ.1.07/ 2.3.00/20.0163). 
The research questions were: 1) What are the project members' personal expectations of the Project?; 2) How do the project members identify and assess the progress over the project period? and 3) How do the project members evaluate the overall effectiveness of the project?

\section{METHODOLOGY}

Survey design was applied to describe the set of collected data. The data was collected by four (4) rounds of semi-structured online questionnaires in consequent six-month intervals between 19 November 2012 and 14 September 2014. The questionnaire was pretested and accepted by the project guarantors. The link and information related to each online questionnaire was emailed to each member of the project by project secretary.

The questionnaire 1 (Q1) focused on project members' expectations, personal objectives and concerns in regard with the project at the start-up phase. Total number of respondent in Q1 was $32(n=32)$. Based on the findings of Q1, the essential follow-up questionnaire was formed to gather the project members' self-assessments of the progress. Each follow-up questionnaire (Q2-Q4) contained the same questions in order to obtain comparative data regarding the subjective self-assessment of each individual member's progress in set expectations (defined in questionnaire 1). The questionnaires consisted of structured statements with Likert scales (1-7 scale) to assess personal progress, gained support from one's own key activity team, and assessment of the project in general on topics of most concerns presented in the start-up phase (Figure 1).

The total number of project members varied from 37 to 49 (average 43) over the project follow-up period due to some alterations in the project personnel and project organisation. Some of the respondents were members in more than one key activity team, which also had an impact in response rates. In three first questionnaires members of multiple teams responded as representative only of one key activity team. The total number of responses in all three follow-up questionnaires was $78(\mathrm{~N}=78)(\mathrm{Q} 2$, $\mathrm{n}=36 ; \mathrm{Q} 3, \mathrm{n}=14 ; \mathrm{Q} 4, \mathrm{n}=28)$. The response rate per each self-assessment questionnaire was high (75\%), which gave rather comprehensive description of the progress occurred over the project period.

The quantitative data was analysed by Tixel $^{\circ}$ spreadsheet. Descriptive statistic was used according to character of data and sample size. Frequencies, averages and percentages were calculated of the structured data (Likert-scales) as the purpose of this survey was to obtain approximate orientation and profile regarding the self-assessed personal progress and input to achieve the objectives.

The open-ended data was analysed by qualitative content analysis. The summative content analysis method was used to combine quantitative and qualitative results to achieve overall results. The summative analysis process consisted of the following phases:

1) reading each respondent's transcript to acquire general sense about the whole content,

2) extracting significant statements from each transcription,

3) formulating meanings from significant statements,

4) aggregating formulated meanings into themes,

5) integrating description of the investigated topic,

6) describing fundamental structure of phenomenon,

7) returning to each original response for final validation. $(22,23,24,28)$.

\begin{tabular}{|c|c|c|c|c|c|c|c|}
\hline \multirow{2}{*}{ AT THE MOMENT I FEEL THAT BY WORKING IN THIS PROJECT ... } & \multicolumn{6}{|l|}{ Poorly } & \multirow{2}{*}{$\begin{array}{c}\text { Excellently } \\
\mathbf{7}\end{array}$} \\
\hline & 1 & 2 & 3 & 4 & 5 & 6 & \\
\hline ...my confidence in scientific writing has improved & ( & ○ & ( & O & ( & ○ & ○ \\
\hline ...my skills to apply research in teaching has improved & ○ & ○ & O & ○ & ○ & ○ & ○ \\
\hline ...my team working skills have improved & O & O & ( & O & ( & ( & O \\
\hline ...my presentation skills have improved & O & ○ & ( & O & O & O & O \\
\hline ...I have gained new impulses and insight for my research & $\bigcirc$ & ○ & ○ & ○ & ○ & ○ & ○ \\
\hline ... my Key Activity has helped me in developing my critical thinking skills & ○ & $\bigcirc$ & ○ & ○ & ○ & ○ & ○ \\
\hline ... my Key Activity has reached the goals set for this 6 month period & ○ & ○ & O & ○ & O & ○ & ○ \\
\hline ... Key Activities are cooperating and sharing their achievements with other Key Activities & O & ○ & ( ) & O & O & O & O \\
\hline$\ldots$ this project has helped me improve my English skills & O & O & O & O & ( & O & O \\
\hline$\ldots$ this project has helped me improve my research competences & O & O & O & O & O & ( ) & O \\
\hline$\ldots$ I am satisfied with the project time management & ○ & O & ( ) & O & ( & ( & ○ \\
\hline
\end{tabular}

Figure 1 Assessment scale in follow-up questionnaires 


\section{RESULTS AND DISCUSSION}

\section{Expectations and personal objectives}

Personal expectations and objectives set for the project period were divided into three (3) main categories $(\mathrm{N}=61 ; 100 \%)$ : general improvement in scientific and research skills $(\mathrm{n}=32 ; 52 \%)$, learning and attaining new competences $(n=23 ; 38 \%)$, and the rise of the scientific level in the faculty $(n=6$; 10\%) (Table 1).

The category to improve scientific and research skills in general $(\mathrm{n}=32 ; 52 \%)$ contained the following four subcategories: 1) to attain deeper knowledge and experience in research methodologies $(\mathrm{n}=15 ; 47 \%), 2)$ to improve scientific writing skills $(n=8 ; 25 \%), 3)$ to improve skills related to planning and writing research applications $(\mathrm{n}=6 ; 19 \%)$, and 4$)$ to attain knowledge how to apply research into practice $(n=3 ; 9 \%)$.

As to attaining new competences $(\mathrm{N}=23 ; 38 \%)$, the personal objectives were set on learning new

Table 1 Personal expectations set for the Project

\begin{tabular}{|l|c|c|c|}
\hline Topic & n & total & $\%$ \\
\hline $\begin{array}{l}\text { A. Improving research/scientific skills } \\
\text { in general }\end{array}$ & & $\mathbf{3 2}$ & $\mathbf{5 2}$ \\
\hline scientific writting skills & 8 & & \\
\hline $\begin{array}{l}\text { research methodology, experienced } \\
\text { in research ing general }\end{array}$ & 8 & & \\
\hline $\begin{array}{l}\text { organising research and scientific } \\
\text { designs, writing grants applications }\end{array}$ & 6 & & \\
\hline scientific knowledge search & 4 & & \\
\hline to make Systematic Reviews & 3 & & \\
\hline applying research outcomes into practice & 2 & & \\
\hline Utilisation of 3N Aliance & 1 & & \\
\hline B. Learning new competences & & $\mathbf{2 3}$ & $\mathbf{3 8}$ \\
\hline team working, new partnerships & 7 & & \\
\hline obtaining new approaches in teaching & 5 & & \\
\hline new competences in general & 5 & & \\
\hline improving English skills & 4 & & \\
\hline $\begin{array}{l}\text { learning Evidence-based Practice/ } \\
\text { Management }\end{array}$ & 2 & & \\
\hline C. Improving scientific level of Faculty & & $\mathbf{6}$ & $\mathbf{1 0}$ \\
\hline Research strategy for the Faculty & 4 & & \\
\hline $\begin{array}{l}\text { Improval of scientific level of the faculty } \\
\text { in general }\end{array}$ & 2 & & \\
\hline Total & & $\mathbf{6 1}$ & $\mathbf{1 0 0}$ \\
\hline
\end{tabular}

skills and approaches in general $(n=10 ; 44 \%)$, to improve team working and obtaining new partnerships $(\mathrm{n}=7 ; 30 \%)$, improving the English language skills $(\mathrm{n}=4 ; 17 \%)$, and learning evidence-based practice and management $(n=2 ; 9 \%)$.

The objectives in regard with raising the faculty's scientific level $(\mathrm{N}=6 ; 100 \%)$ divided into two subcategories: developing a research strategy for the faculty $(\mathrm{n}=4 ; 67 \%)$, and improving the scientific level in general in the faculty $(n=2 ; 33 \%)$.

In Start-up phase, apart from personal expectations the project members expressed also certain concerns $(\mathrm{N}=34)$. Insecurity and diffidence about the level of one's own research competences and abilities to attain new skills seemed to be the biggest concern $(n=11$; $32 \%)$. The other named concerns were leadership and management issues including personal time management $(n=10 ; 29 \%)$, setting realistic and attainable goals for the development $(n=7 ; 21 \%)$, and sustainability of the project outcomes $(\mathrm{n}=6 ; 18 \%)$ (Table 2$)$.

Table 2 Personal concerns about the Project

\begin{tabular}{|l|c|c|c|}
\hline Topic & n & total & $\mathbf{\%}$ \\
\hline A. Personal limitations and shortages: & & $\mathbf{1 1}$ & $\mathbf{3 2}$ \\
\hline $\begin{array}{l}\text { Insecurity of the level of one's } \\
\text { professional skills }\end{array}$ & 4 & & \\
\hline $\begin{array}{l}\text { How to make litarature reviews/ } \\
\text { meta-analysis }\end{array}$ & 3 & & \\
\hline How to learn research methodology & 3 & & \\
\hline Inadequate English Skills & 1 & & \\
\hline B. Management issues & & $\mathbf{1 0}$ & $\mathbf{2 9}$ \\
\hline Time management, lack of time & 7 & & \\
\hline Management of research activities & 2 & & \\
\hline Good team leadership & 1 & & \\
\hline C. Goal settings & & $\mathbf{7}$ & $\mathbf{2 1}$ \\
\hline Too high objectives & 5 & & \\
\hline Attaining good and valuable outcomes & 2 & & \\
\hline $\begin{array}{l}\text { D. Usability and Sustainability of the } \\
\text { Project Outcomes }\end{array}$ & & $\mathbf{6}$ & $\mathbf{1 8}$ \\
\hline $\begin{array}{l}\text { Benefts and use of the project precesses } \\
\text { ind daily teaching }\end{array}$ & 4 & & \\
\hline $\begin{array}{l}\text { Continuity of the project outcomes } \\
\text { afterwards }\end{array}$ & 2 & & $\mathbf{3 4}$ \\
\hline Total & $\mathbf{1 0 0}$ \\
\hline
\end{tabular}




\section{Self-assessed progress}

Based on the start-up phase survey of personal need assessment and objectives for the project, self-assessment questionnaires were drafted to gather follow-up data of the personal and project progress (Figure 1). The follow-up data contained self-assessments on personal improvement in scientific writing, team working, presentation skills, and attaining new insights into research. The project members were also asked to assess the functions of their own key activity team as well as the overall project management.

The top categories in self-assessed attained results consisted of topics related to improved scientific thinking and research skills, team work and collaboration, and other ways of working (Table 3).

As to the personal objectives, the biggest changes occurred in increased confidence in writing scientific texts $(+13 \%)$, applying research in teaching $(+8 \%)$, improved presentation skills $(+10 \%)$, improved team working $(+5 \%)$. Obtaining new insights into research remained the same good level throughout the project without changes. The average assessments in key activity teams regarding personal objectives varied between 3,7 to 5,6 indicating that the project had good or very good level impact in achievement of personal expectations and objectives (statements 2.1-2.5 in Figure 2).

Assessments of key activity teams (see statements 2.6-2.8 in Figure 2) resulted as improved collaboration with other project key activity teams $(+14 \%$ improvement), supporting key activity team members in improving their critical skills (+9), and achieving the biannual goals $(+6 \%)$. The overall assessments related to the key activity team operations varied from good to excellent $(3,4-6,7)$.

Table 3 Self-assessed attained results

\begin{tabular}{|l|l|c|}
\hline Categories & Components & $\mathbf{n}=\mathbf{2 3}$ \\
\hline \multirow{4}{*}{$\begin{array}{c}\text { Scientific thinking and } \\
\text { research skills }\end{array}$} & Improved research skills/competences & 3 \\
\cline { 2 - 3 } & Improved critical thinking & 4 \\
\cline { 2 - 3 } & Improved academic writing skills & 4 \\
\cline { 2 - 3 } & Deeper insight into methodology of research & 3 \\
\cline { 2 - 3 } Team work and collaboration & New methods, design, techniques was learnt & 3 \\
\cline { 2 - 3 } & Establishment of local JBI centre & 1 \\
\cline { 2 - 3 } & Familiarized with databases searching & 4 \\
\hline \multirow{5}{*}{\begin{tabular}{l} 
Ways of working \\
\cline { 2 - 3 }
\end{tabular}} & Improved collaboration, team work & 4 \\
\cline { 2 - 3 } & Cooperation with international experts, international cooperation increased & 2 \\
\hline & English skills improved & 2 \\
\cline { 2 - 3 } & Improved management & 2 \\
\cline { 2 - 3 } & Using JBI tools & 5 \\
\cline { 2 - 3 } & Workshops rewarding (specially with JBI experts) & 3 \\
\cline { 2 - 3 } & Own presentaton skills improved & 2 \\
\hline
\end{tabular}

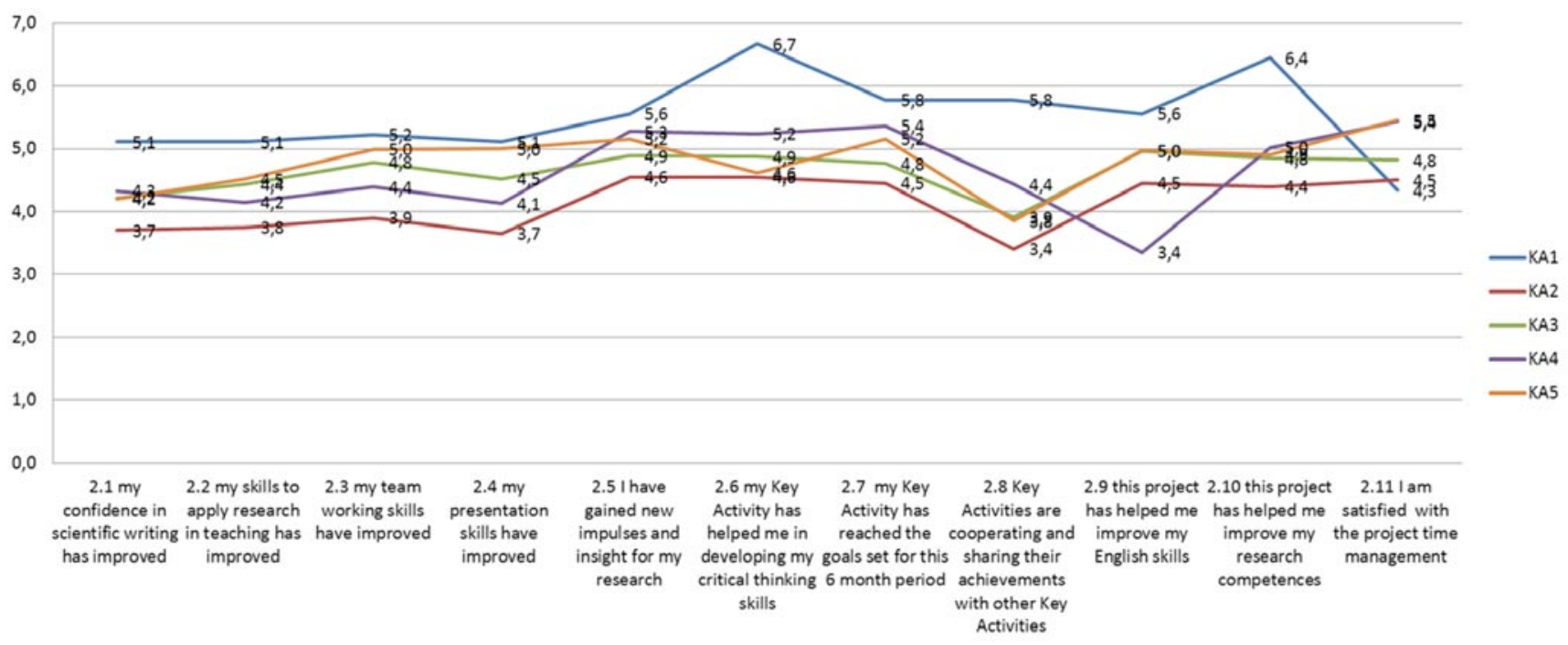

Figure 2 Progress in self-assessments per key activity teams (in averages) 
Assessments of key activity teams (statements 2.6-2.8 in Figure 2) resulted as improved collaboration with other project key activity teams $(+14 \%$ improvement), supporting key activity team members in improving their critical skills $(+9)$, and achieving the biannual goals $(+6 \%)$. The overall assessments related to the key activity team operations varied from good to excellent $(3,4-6,7)$.

\section{Evaluation of project outcomes}

The project members were asked to list up three most positive factors experienced in each interval concerned. The most positively experienced project outcomes named in each interval were related to changes in the ways of working $(n=90 ; 50 \%)$. Team working had increased appreciably due to project activities. Also working in general had become more focused, effective, motivating, rewarding and collaborative in many aspects. Workshops were used more actively, and cooperation with students and teachers as well as with international experts and networks had increased. Here some examples of the original statements by project members:

- "Excellent workshops and teaching session with the ...experts... increased publications and interest in publishing ... improved practical skills in using JBI tools."

- „Excellent expert lectures and workshops organised ...good cooperation regarding working on publications and getting familiarized with JBI tools."

- „Meeting with people... Cooperation and working with other people made me think in different way."

- "I tried with colleagues in the practice of the first phase of a new research Concept Mapping methods. I applied the scientific management team international experience gained in business trips, paid from the project."

- "I think that other important positive issues are international experience and contacts."

- "The most positive issue is cooperating with other universities abroad. I can improve my English skill, which is important in studying materials for my research. I have more possibilities to share our research with other universities abroad and learn new techniques from them."

- "We helped each other with our team of Key activity and our experiences in the aim of science were improved. We had presentation at the foreign world conference and enlarge our concepts with another scientists and our field of interests. We can discuss our problems with other scientists of the World and it is a thing, which can kick us forward."

- "Creating a team of experts on nursing issues and application in clinical practice. My key activity has helped me in developing my critical thinking skills."
Second most positive project outcomes were to do with the improvement in scientific thinking and research skills $(n=70 ; 39 \%)$. New insights into research methodology, understanding of usability of research and importance of knowledge transfer from research into practice were mentioned as the primary elements developed in scientific thinking and research skills. International collaboration and establishing a new research centre within the faculty were also the top positive and motivating factors mentioned over the project period. The project members expressed it as follows:

- „I improved my research skills (search strategies, working with databases...)."

- "I got new experiences in creation/formation of script for our students of the Faculty"

- "I have gained research skills, a deeper insight into methodology of research and writing scientific papers. I have improved my English skills in scientific/ academic writing."

- „I appreciate the foundation of the local center for EBM. Great success is tight collaboration with Adelaide center..."

Third category of positively experienced outcomes was personal achievements $(n=20 ; 11 \%)$. Personal achievements named were increased use of and improvement in the English language, ability and insight to integrate research into teaching and clinical practice, improvement in presentation, management and writing skills. Also active participation in international and national conferences and increased number of publications thanks to the project led to positive experiences. The project members' expressed these outcomes following way:

- "I have improved my English skills, presentations and databases searching."

- "I got new experiences in the design of scientific work, for example work with English text/books... teamwork and communication with my colleagues"

- "The project has a positive effect on critical thinking and presentation skills."

- "Most important positive issues I experienced in the project: I am really positive satisfied with meeting very good colleagues from academic field. These colleagues give me many opportunities to grow up and improve more research competences. Improving my English skills is very important."

The project was evaluated being successful in terms of improved English skills and research competences scaled again between good and excellent $(3,4-6,4)$. The project time management was evalua- 
ted as very good $(4,3-5,3)$ by all key activity teams (statements 2.9-2.11 in Figure 2).

The progress assessment results in averages are presented in the Figure 3. Changes in focus and priorities in project activities according to the project phase easily explain the slight fluctuation in average assessments over the project course. Worth noticing is that the content and activities related to development tasks of each key activity (KA) differed from key activity to key activity as described before.

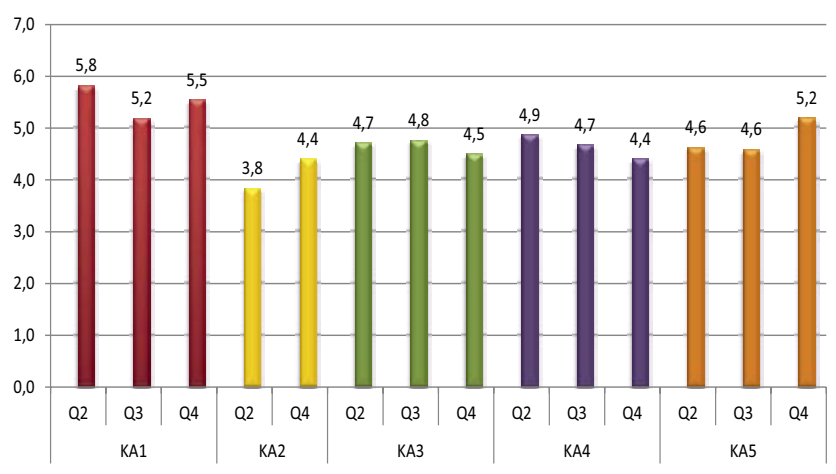

Figure 3 Progress in average assessments over the project per key activities

The entire project received the grade ,very good“ (average grade 4,7 out of 7,0 as maximum; Figure 4). The comments in verbatim praised the project as perfect, useful and rewarding one. Especially rewarding element was collaboration between colleagues in various key activity teams sharing ideas, knowledge and insights in striving towards a common goal. The experts engaged as lecturers and advisors in various phases in the project received also good feedback. The project offered a useful forum to integrate research and practice and increase international aspects in the development of healthcare higher education at the university concerned.

The overall results are much parallel to previous studies on capacity building projects using educational programmes and hands-on team working approach to achieve the aimed new competences $(4,14,19)$. The framework of long-term hands-on training programmes providing adequate guidance, engagement, support and communication between different actors is effective in developing new competences $(25,26)$. Needs to improve personal research skills and the overall scientific level in the faculty were commonly recognised and acknowledged which worked well as motivation in the project. The project provided facilitation and a safe environment to learn, exercise and apply acquired skills directly back on the daily academic tasks $(21,27)$.

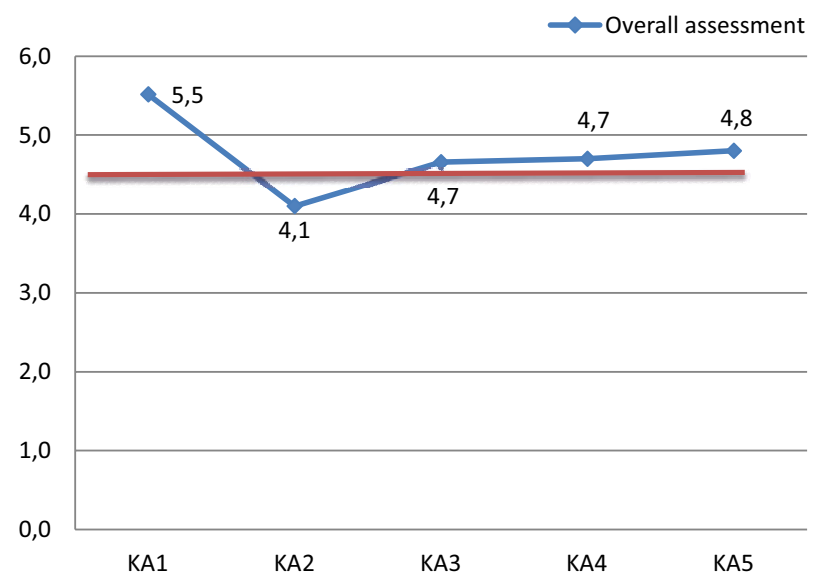

Figure 4 Overall project scores per key activity teams

\section{LIMITATIONS}

As to limitations of this study, one could mention changes in the number of Project members. First three (Q1-Q3) questionnaires did not offer possibility to identify possible representation of multiple key activities. Each respondent was only identified as representative of one of the named key activity teams.

Another limit of this study is relatively small sample size which was varied from 36 to 14 during the time of project.

The data was gathered by means of semi-structured questionnaires with Likert-scales and open-ended questions. The data was analysed by quantitative content analysis method calculating frequencies, averages and percentages to obtain approximate profiles of subjective outcomes of the project activities.

Subjective assessment data resulted in clear guidelines about the processes experienced and achievements made both in personal and faculty level. Clear results and evident progress both in personal achievements as well as in key activity team functions took place over the project period. Most of the personal expectations were excellently achieved in terms of attained confidence, new competences, and lots of positive experience. New ways to apply and utilise research both in clinical and teaching practice were discovered. New impulses and motivation for conducting and publishing research was obtained. These evaluation results indicate a successful project and good level of and sustainable enhancement in research competences in the target group. 


\section{CONCLUSIONS}

The most noteworthy result was that this kind of Capacity Building Project is much needed in healthcare higher education faculties. Reasons backing up the importance of the Project identified in the data were the novelty as a Faculty and Health Sciences and as a field of Science, transitions in teaching approaches and teacher's job descriptions in higher education. Requirements for health professionals' qualifications due to cross-national qualifications among the EU member states consist of evidence-based practice and integration of research \& innovation methodologies in professional qualifications in general. A structured strategy for managing researcher competencies appears to be essential and the higher education systems have a key role to play in training young researchers in this area (16).

The project achievements were parallel to subjective expectations with focus on. Participants were satisfied with improved language skills (English), time management and progress in the key activities according to the Project schedule. New impulses and insight were attained, and research and critical thinking skills were improved. The interaction between the key activities increased in terms of sharing expertise, information of team achievements and the ways how they were reached.

The project activities focused on improvement of academic skills of the faculty approved to be needed. Most of the project participants became encouraged to identify their development needs in knowledge of research methodology, and both conducting, teaching and communicating research endeavours. At the final phase of the project, the subjective assessment of the project processes and achievements are encouraging. This project has been successful in laying a robust foundation for consistent development in research-based practice both in academic and professional levels. From sustainability points of view, further research should be conducted on the longterm impacts of the project in the faculty.

\section{ACKNOWLEDGEMENT}

The paper is dedicated to the project: "Support of Human Resources in Science and Research in Non-medical Healthcare at the Faculty of Health Sciences at Palacký University Olomouc", reg. no. CZ1.07/2.3.00/20.0163.

\section{REFERENCES}

1. Leeman Y, Wardekker W. Teacher research and the aims of education. Teachers and Teaching: theory and practice. 2014; (20)1:45-58.
2. Lyons C, Brown T, Tseng MH, Casey J, McDonald R. Evidence-based practice and research utilisation: Perceived research knowledge, attitudes, practices and barriers among Australian paediatric occupational therapists. Australian Occupational Therapy Journal. 2011;(58):178-86.

3. McDonnell L, Stratton P, Butler S, Cape N. Developing research-informed practitioners - an organisational perspective. Counselling and Psychotherapy Research. 2012;(12)3:167-77.

4. Crozier K, Moore J, Kite K. Innovations and action research to develop research skills for nursing and midwifery practice: the Innovations in Nursing and Midwifery Practice Project study. Journal of Clinical Nursing. 2012;21:1716-25.

5. Grimshaw JM, Eccles MP, Lavis JN, Hill SJ, Squires JE. Knowledge translation of research findings. Implementation Science [Internet]. 2012 [cited 2014 Jan 29]; 7(1):50. Available from: http://www. implementationscience.com/content/7/1/50

6. Jones ML. Sustainable organizational capacity building: is organizational learning a key? The International Journal of Human Resource Management. 2001;(12)1:91-8.

7. Anderson WA, Banerjee U, Drennan CL, Elgin SCR, Epstein IR, Handelsman J, et al. Changing the Culture of Science. Science. 2011;331(14):152-53.

8. Coil D, Wenderoth MP, Cunningham M, Dirks C. Teaching the Process of Science: Faculty Perceptions and an Effective Methodology. CBE-Life Sciences Education. 2010;9:524-35.

9. Frank JR, Snell LS, Cate OT, Holmboe ES, Carraccio C, Swing SR, et al. Competency-based medical education: theory to practice. Medical Teacher. 2010;(32)8:638-45.

10. Webb F, Smith C, Worsfold K. Research Skills Toolkit [Internet]. Griffith University, 2011. [cited 2014 Jan 29]. Available from: http://www. griffith.edu.au/gihe/resources-support/graduate-attributes

11. Thomas L, Roddam H, Baker P, French B, Burton C. Indicators facilitating research-based practice in allied health profession departments. International Journal of Therapy and Rehabilitation. 2011;(18)2:71-8.

12. Schneider Z, Whitehead D. Nursing and Midwifery Research: methods and appraisal for evidence-based practice. Sydney: Elsevier Australia; 2013.

13. Bohman DM, Ericsson T, Borglin G. Swedish nurses' perception of nursing research and its implementation in clinical practice: a focus group study. Scandinavian Journal of Caring Sciences. 2013;27(3):525-33. 
14. Coluzzi-Gray L, Sharmisha D, Gray D, Robson D, Spratt J. Evidence-based practice and teacher action-research: a reflection on the nature and direction of „change“. British Educational Research Journal. 2013;39(1):126-47.

15. Larson EL, Begg MD. Building Interdisciplinary Research Models: A Didactic Course to Prepare Interdisciplinary Scholars and Faculty. Clin Transl Sci. 2011;(4)1:38-41.

16. Ulrich W, Dash DP. Research Skills for the Future: Summary and Critique of a Comparative Study in Eight Countries. Journal of Research Practice [Internet]. 2013 [cited 2015 Feb10];(9)1. Available from: http://jrp.icaap.org/index.php/jrp/article/ view/377/304.

17. Kirkpatrick P, Wilson E, Wimpenny P. Research to support evidence-based practice in COPD community nursing. British Journal of Community Nursing. 2012;17(10):486-92.

18. Christie J, Hamill C, Power J. How can we maximize nursing students' learning about research evidence and utilization in undergraduate, preregistration programmes? Journal of Advanced Nursing. 2012;68(12):2789-801.

19. Manspeaker S, Van Lune B. Overcoming Barriers to Implementation of Evidence-Based Practice Concepts in Athletic Training Education: Perceptions of Select Educators. Journal of Athletic Training. 2011;46(5):514-22.

20. Ormerod RJ. Research skills for the future: A consultant's perspective. Journal of Research Practice [Internet]. 2013 [cited 2014 Jan 24];9(1), Article V2. Available from: http://www.jrp.icaap.org/index.php/ jrp/article/view/380/305

21.Cargill M. Transferable skills within research degrees: a collaborative genre-based approach to developing publication skills and its implications for research education. Teaching in Higher Education. 2004;9(1):83-98.
22. Babbie E. The practice of social research. New York: Macmillan; 1992.

23. Giorgi A. The phenomenological psychology of learning and the verbal learning tradition. In: A. Giorgi, editor. Phenomenology and Psychological Research. Pittsburgh, PA: Duquesne University Press; 1985. p. 23-83.

24. Morse JM, Field PA. Qualitative research methods for health professionals (2nd edition). Thousand Oaks, CA: Sage; 1995.

25. Corchon S, Portillo MC, Watson R, Saracíbar M. Nursing research capacity building in a Spanish hospital: an intervention study. Journal of Clinical Nursing. 2011;20:2479-89.

26. Jones M, Stanley G, McNamara O, Murray J. Facilitating teacher educators' professional learning through a regional capacity-building network. Asia-Pacific Journal of Teacher Education. 2011; 39(3):263-75.

27. Lomborg K, Skånning E, Lunde Jensen A, Bastrup Jorgsensen L. Achieving competences in patientcentred care: an evaluation study of a training programme in assisted personal body care for respiratory patients. Journal of Nursing and Healthcare of Chronic Illness. 2011;3:265-74.

28. Makoe M. A phenomenological analysis of experiences of learning in the South African distance education context. In: Enhancing Higher Education, Theory and Scholarship: Proceedings of the 30th HERDSA Annual Conference; 2007 July 811; Adelaide, Australia; 2007. p. 341-350.

\section{CONTACT DETAILS OF MAIN AUTHOR}

Dr. Andrew Sirkka Dr.Ed.

Satakunta University of Applied Sciences, Health Tiilimaki Campus

Maamiehenkatu 10

FI-28500 PORI, FINLAND

andrew.sirkka@samk.fi 